\title{
«SUIZA EN LA AVENTURA DE LA MANCHA»: PATRIMONIO Y TURISMO CULTURAL EN LOS AÑOS DEL DESARROLLISMO ESPAÑOL
}

\author{
Jesús Nicolás Torres Camacho \\ Universidad de Oviedo ${ }^{1}$
}

\section{RESUMEN}

En 1972 un grupo de directivos de agencias de viajes suizos y alemanes llegaron a España para visitar la comarca de La Mancha con el fin de conocer los recursos turísticos que ésta podría ofrecer, algunos conocidos mundialmente desde la publicación de la novela cervantina de El Quijote. Durante la Dictadura del General Franco las actividades turísticas experimentaron un importante auge a través de un turismo de masas principalmente extranjero centrado en las áreas costeras, pero en este caso la administración preparó un proyecto para atraer turistas hacia el interior, concretamente a La Mancha.

Palabras clave: turismo cultural, patrimonio, desarrollismo, Suiza, La Mancha.

«The adventures of Switzerland in La Mancha»: heritage and cultural tourism in the spanish years of policy and economic development

\begin{abstract}
In 1972 a group of Swiss and German travel agency directors came to Spain to visit the region of La Mancha in order to learn about the tourist resources that this region could offer. During General Franco's dictatorship, tourist activities experienced a boom through foreign mass tourism mainly focused on the coastal areas. But in this case the administration prepared a project to attract them to inland tourism, specifically La Mancha.
\end{abstract}

Key words: cultural tourism, heritage, developmentalism, Switzerland, La Mancha.

Recibido: 17 de febrero de 2014

Devuelto para su revisión: 10 de julio de 2014

Aceptado: 1 de septiembre de 2014

1 Geógrafo y becario FPI. Este trabajo ha sido realizado en el marco del Proyecto de Investigación del Plan Nacional de I+D+i Restauración monumental en el Desarrollismo 1959-1975 (HAR2011-23918), financiado por el Ministerio de Economía y Competitividad. I. P: Dra. Dña. M. Pilar García Cuetos (Universidad de Oviedo).

Universidad de Oviedo. C/Teniente Alfonso Martínez, s/n. 33011 OVIEDO (España). E-mail: torresjesus@ uniovi.es. 


\section{INTRODUCCIÓN: INICIATIVAS TURÍSTICAS DURANTE EL FRANQUISMO}

La Dictadura del General Franco apostó intensamente por el turismo como pieza clave del desarrollo económico de la nación atrayendo a las corrientes turísticas principalmente europeas. Esta actividad fue fundamental para equilibrar la balanza de pagos con la entrada de capital extranjero. Sol, playa, paisajes, historia y monumentos eran (y siguen siendo) importantes reclamos, tal y como recogía Rafael Calleja en su obra Nueva Apología del Turismo de España «Entre los países de Europa, se diferencia España por singularidades exclusivas (...). En España puede el viajero trasladarse, en breve jornada, de las nieves perpetuas al templado perfume de palmeras y naranjos. Huye aquí la monotonía acosada sin cesar por el contraste» (Calleja, 1957: 6). Tópicos, tipismo, folklore... se convirtieron en recursos y fueron utilizados para este fin. Aunque este trabajo no pretende hacer un repaso por la historia del turismo durante la Dictadura, ya que esta etapa ha sido estudiada profusamente por diferentes autores ${ }^{2}$, sí nos parece necesario realizar un breve recorrido por los mecanismos que empleó el franquismo en materia turística.

La Guerra Civil española supuso un punto de inflexión en todos los ámbitos de la vida del país. En el caso de las actividades turísticas conllevó la paralización de las iniciativas puestas en marcha con anterioridad. No obstante, se creó el Servicio Nacional de Turismo (1938-1939) a cargo Luis Antonio Bolín Bidwell, integrado en el Ministerio del Interior que recoge las funciones del extinguido Patronato Nacional de Turismo, y tras concluir la guerra, se convierte en la Dirección General de Turismo (1939-1951). Los años de postguerra, de miseria, de aislamiento, complicaron su labor pero surgieron algunas iniciativas destacadas que aprovecharon el conflicto bélico, como la Ruta de la Guerra del Norte de España que atraía a franceses a conocer el campo de batalla y el estado de la contienda, aunque más que iniciativa turística, es considerada como «actuación política y propagandística» (Fernández, 1991: 321). Durante estos años, se realizó una enorme labor de propaganda en el exterior, tal y como atestigua la variedad de carteles turísticos existentes; más adelante, en 1948, se creó el slogan publicitario Spain is beautiful and different.

El avance en materia turística fue lento pero progresivo durante la primera mitad del siglo XX, en su segunda mitad el país se encontró en «un contexto internacional más favorable por el levantamiento, por parte de la ONU, de las sanciones políticas y económicas» (de Arrillaga, 2005: 47), generándose la estabilidad necesaria para incrementar el movimiento de personas. Desde el Ministerio de Información y Turismo (1951-1977) se avanzará cuantitativamente, y este periodo acogerá el auge de las actividades turísticas apoyadas por la iniciativa pública, convirtiéndose en uno de los impulsos de desarrollo económico de la nación. En 1962 con Manuel Fraga Iribarne ${ }^{3}$ al frente del Ministerio, se crea la Subsecretaría de Turismo como órgano de asistencia de dicho Ministerio, que colaborará también en la confección de diversos Planes Nacionales de Desarrollo Eco-

2 Fernández Fúster, L., 1991; Pellejero, C., 1999, 2000; Sánchez Sánchez, E. M., 2001; Velasco, M., 2004; Bayón, F., 2005; Moreno, A., 2007, 2011; Sasha, D., 2009; Almeida, F., 2012; Vallejo, R., 2013, etc.

3 Ocupó la cartera de Ministro de Información y Turismo entre 10 de julio de 1962 y el 29 de octubre de 1969. 
Figura 1

FOLLETO TURÍSTICO DE LAS RUTAS DE GUERRA EN ESPAÑA

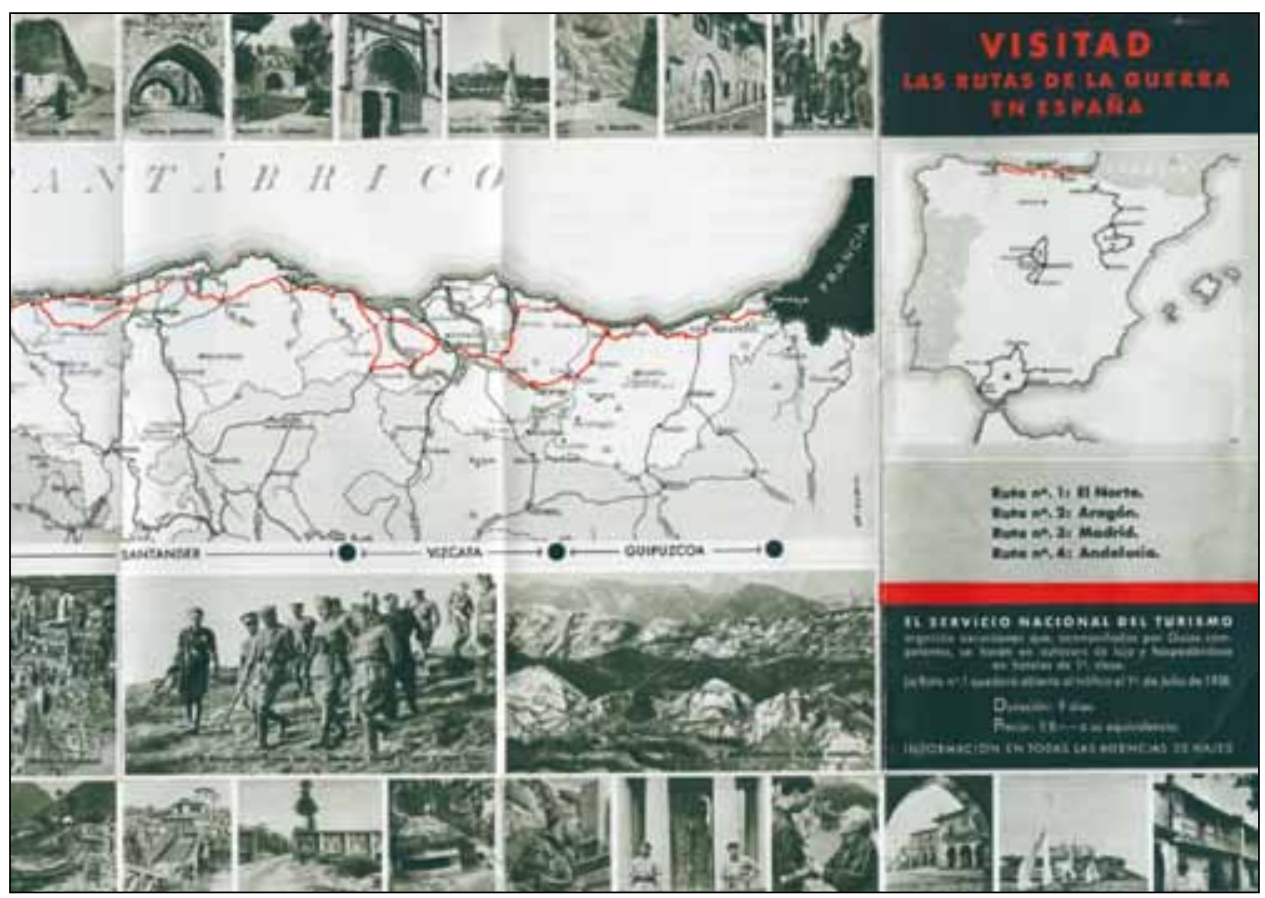

Fuente: Servicio Nacional del Turismo, 1938.

nómico. A su vez, dicha subsecretaría coordinará la acción de la Dirección General de Promoción del Turismo y de la Dirección General de Empresas y Actividades Turísticas que dependían de ella, representando el enlace entre el sector público y el privado, gestoras del ocio entendido en este momento como «producto económico». Finalmente, en 1968 «desapareció la Subsecretaría de Turismo en una política de austeridad económica, pero el Ministerio no dejó de mantener esa doble actuación dividida en ordenación y actividades turísticas» (Moreno, 2011: 7).

El Régimen favoreció el crecimiento del turismo de masas como mecanismo de ingresos para el Estado. Diversos territorios se erigieron como destinos vacacionales (de sol y playa) apreciados en Europa y la administración trabajó intensamente en su promoción en el extranjero, con el fin de asentarlos en la oferta de las tour operadoras a través de interesantes campañas publicitarias, aunque no solo se pretendía atraer a los extranjeros a las costas sino también al interior. Así lo demuestran diferentes iniciativas como la creación del Registro de Denominaciones Geoturísticas en 1964, por el que se inscribían diversos espacios dotados de interés acompañados de un slogan del que podían hacer uso en cualquier campaña publicitaria (por ejemplo, La Toja, isla de ensueño); o el establecimiento de las Zonas y Rutas Turísticas que buscaban la racional distribución de la gran corriente turística que afluye a nuestro país, adecuando las exigencias de la demanda a las variadas 
características de la nación ${ }^{4}$. Entre las rutas establecidas se impulsó una dedicada a la obra de Miguel de Cervantes, la Ruta del Quijote incluida en la Zona 8, Madrid y su contorno monumental y artístico, que comprendía las provincias de Madrid, Toledo, Segovia, Ávila, Guadalajara. Soria, Ciudad Real y Cuenca.

\section{CARACTERIZACIÓN GEOGRÁFICA DE LA COMARCA DE LA MANCHA}

La Mancha es una «gran comarca o subregión» (Pillet, 2001: 19) que ocupa parte del interior de la Comunidad Autónoma de Castilla-La Mancha. Sus territorios quedan conformados por parte de las provincias de Albacete, Ciudad Real, Cuenca y Toledo, y es identificada por su llanura, de mismo nombre, considerada por algunos autores como la «más extensa y perfecta de la Península Ibérica» (Vázquez y González, 2007: 53).

Desde el punto de vista geográfico, se localiza en la zona central de la región y queda integrada en la cuenca sedimentaria del Terciario superior, como extensa depresión encerrada entre los restos de la penillanura herciniana y los relieves alpinos orientales (Panadero, 2011: 26). La disposición y morfología de sus materiales y su escasa compactación han favorecido el carácter tabular de su paisaje y han permitido una diferente erosión de la red hidrográfica. Ésta se manifiesta en un escaso grado de incisión fluvial del río Guadiana y de sus afluentes, que «sólo han logrado abrir pequeños y sinuosos cauces sobre la llanura manchega» (Panadero, 2011: 26), siendo habituales «los desbordamientos y la génesis de extensas llanuras de inundación» (Peinado, 2009: 23), es decir, de humedales como los que caracterizan el Parque Nacional de las Tablas de Daimiel.

Con una superficie de $15.590 \mathrm{~km}^{2}$, está compuesta por 97 municipios que engloban una población cercana a 700.000 habitantes con una densidad superior a los $43 \mathrm{hab} / \mathrm{km}^{2}$, por encima de los valores medios de la región (Panadero y Pillet, 2011: 43). En ella destacan algunos de los principales núcleos de la red urbana castellano-manchega, como es el caso de Albacete, cuyo desarrollo socioeconómico a partir de los servicios y de las industrias manufactureras hacen de esta la ciudad más poblada de la región (172.693 habitantes en 2013), así como diversos núcleos con una importante orientación vitivinícola como Tomelloso (38.900 hab.), Alcázar de San Juan (31.973 hab.), Valdepeñas (30.869 hab.), Villarrobledo (26.513 hab.) o Manzanares (19.118 hab.). Sus extensos viñedos generan una de las imágenes más típicas de la región, amenazada por las problemáticas a la que se enfrenta el sector vitivinícola, derivadas de las nuevas técnicas de cultivo y de la gestión del agua en un área deficitaria (Ruíz, 2013), provocando la alteración del paisaje manchego. No obstante, al igual que ocurre en otras áreas desarrolladas del planeta, es el sector terciario el más relevante desde el punto de vista económico (administración, comercio, turismo, etc.) y dentro de él, La Mancha y el producto cultural «Ruta del Quijote» constituyen, en base a la atracción turística que generan, «su recurso mejor explotado, incluyéndose en él la gastronomía, los elementos característicos de la arquitectura popular, las costumbres y un paisaje de horizontes inalcanzables» (Panadero y Pillet, 2011: 43).

Para finalizar, es conveniente precisar que dentro de la comarcalización geográfica en la que vienen trabajando los profesores Pillet y Panadero (Pillet, 2010: 29, Pillet y

\footnotetext{
4 Orden de 9 de marzo de 1971 sobre Determinación de Zonas y Rutas turísticas.
} 
Panadero, 2011: 22-44) se distinguen tres grandes conjuntos dentro de Castilla-La Mancha (Comarcas de Sierra, Comarcas de Llanura y Comarcas de Transición), La Mancha se incluye en las denominadas Comarcas de Llanura. Es, sin duda, la más relevante de este conjunto conformando una entidad supramunicipal en la que convergen distintos paisajes como resultado de la conjunción de elementos naturales y culturales.

\section{LA MANCHA COMO DESTINO TURÍSTICO}

Diferentes autores han analizado desde el enfoque geográfico ${ }^{5}$ las potencialidades y los recursos territoriales de la comarca manchega. Desde un punto de vista global y generalista podemos reconocer en esta comarca como en otras, la propia construcción del territorio como componente intrínseco del haber patrimonial, circunstancia que nos permite dejar de considerarlo solo como el sustrato de las actividades humanas y valorarlo como «cultura, historia, memoria colectiva, referente identitario, bien público, espacio de solidaridad y legado» tal y como pone de relieve el manifiesto Por una Nueva Cultura del territorio (VV.AA., 2006), por esta razón podemos conceder al territorio valor patrimonial por sí mismo, ya que no solo es soporte físico sino también producto cultural al que se anclan identidades y sentimientos de un grupo social, es decir, «patrimonio territorial» (Cañizares, 2011: 1-2), concepto que la disciplina geográfica viene relacionando mediante la unión de dos realidades, Territorio y Patrimonio, donde el territorio es considerado como recurso cultural y económico (Pillet, 2011: 728).

La Mancha cuenta con diferentes valores naturales y culturales que integran su patrimonio territorial; los molinos de viento de Consuegra y de Campo de Criptana, el Toboso como el pueblo de Dulcinea, La Venta de don Quijote de Puerto Lápice, la Cueva de Medrano de Argamasilla de Alba o los propios paisajes manchegos han sido utilizados en infinidad de ocasiones como medio de propaganda turística y sobre todo, piezas clave en las diferentes rutas diseñadas en torno a la figura de don Quijote, protagonista de la obra de Miguel de Cervantes El Ingenioso Hidalgo Don Quijote de La Mancha (1605). Cervantes crea en la novela un «contexto»o «ambiente» territorial que describe y ha transmitido a los lectores a lo largo de la historia desde su publicación, La Mancha, «asociada al nombre del caballero andante, forma parte del imaginario mundial» (García Martínez, 2006: 275), y la llanura permite unificar los conceptos de cultura y territorio «ofreciendo numerosos atractivos al visitante foráneo y una singularidad que hoy prima en un mundo globalizado como el nuestro» (Cañizares, 2008: 59), particularidades que «permitieron a los diversos viajeros que la visitaron (...), identificar el escenario y sus gentes en cualquiera de sus rincones» (García Marchante y Fernández, 2000: 5).

La Mancha es visitada en gran medida gracias a El Quijote y a los molinos de viento, convirtiéndose ambos en iconos de una región considerada tradicionalmente «de paso» en el camino de Madrid a Andalucía, a través por ejemplo, del diseño de rutas e itinerarios culturales. Las rutas turísticas han permitido relacionar el patrimonio territorial y el ocio siguiendo la «tendencia a convertir los territorios en escenarios turísticos como modo

5 García Marchante, J. S. y Fernández, M. C., 2000; Pillet, F., 2002, 2011, 2012; Campos, L., 2006; Pillet, F., y Plaza, J., 2006; Cañizares, C., 2008, 2009; Panadero, 2011, etc. 
de desarrollo de la sociedad del ocio» (Pillet, 2012: 347). Podemos encontrar diferentes antecedentes de la ruta del Quijote en los últimos años promovidos desde el gobierno regional, así como diversas publicaciones ${ }^{6}$ principalmente en la mitad de la primera década del siglo XXI anticipando la celebración del IV Centenario de la edición de la primera parte del Quijote que tendría lugar en 2005. En 1997 la Dirección General de Turismo desarrolló la Ruta de El Quijote, entre sus actividades se concedieron subvenciones para la mejora turística de la ruta, circunstancia que fue aprovechada por los municipios de Campo de Criptana y Consuegra para la rehabilitación, mejora y explotación turística de sus molinos de viento (Campos, 2002: 90). En el año 2000 pasó a ser la Ruta de Don Quijote del Proyecto Rocinante, surgido tras la elaboración del primer Plan de Ordenación y Aprovechamiento de los espacios naturales de Castilla-La Mancha, que englobaba once rutas o corredores ecoturísticos con un total de 6.000 kilómetros y que formaban la llamada «Red Rocinante» (Campos, 2006: 218). En 2005 se celebró el IV Centenario del Quijote, y para su conmemoración se aprobó la Ley 16/2002 de 11 de julio, del IV Centenario de la publicación del ingenioso hidalgo don Quijote de La Mancha. Entre los actos y eventos que se desarrollaron destaca la Ruta de Don Quijote, que fue distinguida entre 2007 y $2012^{7}$ como Itinerario Cultural Europeo por el Consejo de Europa, y «ha contribuido de manera evidente a la revalorización de determinados elementos culturales vinculados al «quijotismo»e incluso al «cervantismo» como recursos asociados a estrategias de desarrollo territorial» (Cañizares, 2008: 58).

En esta ocasión nuestro interés se centra en los antecedentes de este itinerario, remontándonos en especial a los desarrollados durante la Dictadura que han sido menos analizados, pero de enorme interés, como es el caso de la Ruta del Quijote de 1971 y la visita de un grupo de directivos helvéticos y alemanes a través del proyecto denominado Suiza en la aventura de La Mancha de 1972.

\subsection{La Mancha a través de los viajeros. La influencia de El Quijote}

Una interesante fuente para el estudio del fenómeno turístico es la denominada literatura de viajes o de viajeros. Sus relatos y testimonios pueden aportar numerosos datos geográficos, económicos, sociales, culturales... y, poner de relieve, con su mirada, lo que el paisano no aprecia por formar parte de su acervo (Almarcha, 2001: 35). La amplia información que nos facilitan argumenta que diferentes estudios constaten la utilidad y «la conveniencia de rentabilizar la experiencia de los viajeros como testimonio de excepción para el investigador» (Ortas, 2006: 24).

Hemos seleccionado algunas de las referencias realizadas por los diferentes viajeros a su paso por La Mancha, así como la de diversos autores ${ }^{8}$ que han trabajado en los últimos

6 González Cuenca, J. et al., 2003; Unceta, M. (Coord.), 2004; Puche, R., Serrano, M. y Díez, J., 2004; Almarcha, E., y Sánchez, I., 2005; Pillet, F., y Plaza, J. (Coords.), 2006; VV.AA., 2009, etc.

7 Mediante la Ley 5/2012 de 12 de julio, de Presupuestos Generales de la Junta de Comunidades de Castilla-La Mancha, se derogan entre otras: la Ley 7/2006, de 20 de diciembre, de Ordenación de la Ruta de don Quijote; y la Ley 16/2002, de 11 de julio del IV Centenario de la publicación del ingenioso hidalgo don Quijote de La Mancha, con lo que la ruta pierde su condición de Itinerario Cultural Europeo.

8 Almarcha, 2001; Almarcha y Sánchez, 2005; Ortas, 2006, Pillet, 2006; Bautista, 2010, etc. 
años en su estudio, con especial atención a la descripción de los recursos territoriales que al retomar la «aventura» de don Quijote han encontrado a su paso por ésta región. La Mancha, los molinos de viento, los campos de cultivo, los pueblos, los propios habitantes... acapararon su atención y sus relatos y observaciones han contribuido a la construcción de la imagen del territorio manchego sustentado en la novela cervantina y fuertemente asentado en la cultura de la población.

Una de las primeras reseñas que recogemos es el viaje de Cosme de Médicis por España y Portugal (1668-1669), del que existen diferentes textos y perspectivas, siendo una de la más interesantes las del Diario de Viaje de Juan Bautista Gornia, médico que acompañaba al grupo. Es significativa su referencia a los límites de La Mancha desde el Castillo de la localidad toledana de Mora: «Quinel Castello Mora comincia la Provincia della Mancia famosa per Don Chisciotte» (Sánchez y Mariutti, 1933: 159). Posteriormente las ruinas del castillo de Consuegra atrajeron la atención de Antonio Ponz ${ }^{9}$ (1772): «Consuegra es Villa que pertenece al Gran Priorato de San Juan, situada en el declive de una colina, sobre la cual se conservan los residuos de un Castillo que hubo de ser muy fuerte», elemento que en la actualidad, junto a los molinos de viento colindantes, constituyen uno de los recursos visuales de La Mancha. A finales del siglo XVIII destacamos el relato del canario José Viera y Clavijo ${ }^{10}$ (1774) que leía la novela e incluso llegó a medir las etapas de su recorrido «a pocas aventuras leídas en Don Quijote, nos hallamos a las 5 en Tembleque». Una de las narraciones más interesantes sobre los molinos de vientos fue la de Joseph Townsend ${ }^{11}$ (1786-1787) en la que señalaba: «...En este famoso territorio de La Mancha es natural que esperáramos encontrar molinos de viento, y de hecho los pudimos ver; tal y como imaginábamos, cerca de cada pueblo, donde los construyen para suplir la carencia de corrientes de agua con las que moler el trigo...».

Algunos viajeros se desilusionaron por lo que encontraban a su paso por La Mancha, mientras otros quedaban admirados y detallaban todo lo observado. Edward Hawke Locker $^{12}$ visitó España (1813) como correo de Wellington, y expresó las expectativas que para un extranjero tenía usar exclusivamente como guía de viaje El Quijote, consciente de la ficción de la obra escribía «...Guiado de mi admiración por Cervantes, me desvié del camino recto en busca de un lugar que sabía de antemano que no respondería a mi curiosidad...». Años después (1837) la duquesa de Abrantès ${ }^{13}$ constató lo que para ella era auténtica realidad y fidelidad en las descripciones de la novela a su paso por la Venta de Puerto Lápice: «ses portraits! Et comme il les copiait avec fidélité!». De Richard Ford ${ }^{14}$ (1845) destacamos su atención al ya conocido vino de Valdepeñas, se sorprendió de la primitiva y descuidada manera en la que se elaboraba, «a pesar de tener en Madrid su mejor parroquia».

9 Ponz Piquer, A. (1772): Viaje de España: en que se da noticia de las cosas más apreciables y dignas de saberse, que hay en ella.

10 De Viera y Clavijo, J. (1774): Viaje a La Mancha en 1774.

11 Townsend, J. (1988): Viaje por España en los años en la época de Carlos III (1786 y 1787).

12 Locker, E. H., (1813): Views in Spain.

13 Duchesse d'Abrantès (1837): Souvenirs d'une ambassade et d'un séjour en Espagne et en Portugal de 1808 à 1811 .

14 Ford, R. (1982): Manual para viajeros por España y lectores en casa. 
El primer español del que se tiene constancia que recreó la Ruta del Quijote es José Giménez-Serrano ${ }^{15}$ para la revista Seminario Pintoresco Español (1848), quien afirmó: «me propuse visitar la patria de Don Quijote, recorrer las calles de su lugar, seguir el camino de sus primeras y más famosas aventuras, recoger las populares tradiciones y apurar cuanto allí se supiese de las des-gracias del manco de Lepanto, y de lo que pudo dar origen á su riquísima historia». Esta ruta es considerada por algunos autores como la primera realizada con el fin declarado de visitar La Mancha. Especialmente destacado fue Charles Davillier ${ }^{16}$, que visitó España (1862-1873) acompañado del ilustrador Gustave Doré, su visión de los molinos de viento manchegos sobresale entra la de los viajeros del periodo romántico: «Los campos de trigo se sucedían unos tras otros hasta el infinito. Algunas veces se nos aparecía un montículo en el horizonte, coronado por una fila de molinos de viento que nos hacían pensar naturalmente en el héroe de La Mancha». El norteamericano August Jaccaci ${ }^{17}$ (1896) es considerado pionero en recorrer los parajes que ambientan El Quijote y en plasmar por escrito sus impresiones, ofreciéndonos interesantes imágenes culturales de la cultura manchega, a lo que se une su gusto por la realización del viaje a partir de la ruta literaria con una incipiente orientación turística. A su paso por Campo de Criptana recogió: «En el camino nos encontramos los famosos molinos de viento, uno de los cuales se señala como contendiente del famoso caballero. ¡Pobre Don Quijote, cuya locura puede muy bien excusarse cuando se vean por primera vez estos molinos diseminados por las colinas! No son semejantes a nada; es algo extraordinario sembrado en estas lomas por el capricho de un loco».

A principios del siglo pasado, José Martínez Ruiz, «Azorín», con motivo del III Centenario del Quijote, recreó La ruta de don Quijote (1905) para el diario El Imparcial. Se trata de uno de los primeros exponentes de itinerario literario por La Mancha, más bien que como ruta turística propiamente dicha. Retomó los pasos de Don Quijote desde la considerada patria del caballero, Argamasilla de Alba hasta Alcázar de San Juan, corazón geográfico de La Mancha, pasando por Puerto Lápice, Ruidera, Campo de Criptana o El Toboso. Resulta interesante la consideración que hizo el propio Azorín sobre las rutas literarias en 1935, cuando argumentaba que podían servir para avivar el patriotismo, el espíritu de amor a la tierra, además de ayudar al conocimiento de la literatura. Juan Larreta y Francisco Prieto ${ }^{18}$ (1922) redactores del diario La Región publicado en Valdepeñas entre 1922 y 1923, efectuaron una ruta por La Mancha desde la propia región, en la que no falto el correspondiente itinerario quijotesco.

El colombiano Lucio Pabón Núñez ${ }^{19}$ (1962) quedó fascinado por los molinos de Campo de Criptana: «En esta zona sí que no caben las vacilaciones; en otras, podemos ver - como cuando se va de Puerto Lápice a Madridejos - un molino sobre un otero, tal vez dos, pero todo un escuadrón de estas descomunales máquinas no se encuentra sino en

15 Giménez Serrano, J. (1848): Un paseo a la patria de don Quijote.

16 Davillier, C., y Doré, G. (1862-1873): Voyage en Espagne.

17 Jaccaci, A. (1897): On the trail of Don Quixote: being a record of rambles in the ancient province of La Mancha.

18 Larreta, J., y Prieto, F. (1922): La vuelta a la Mancha a pié.

19 Pabón, L. (1962): Por La Mancha de Cervantes y Quevedo. (del que conocemos el año de la edición, no del viaje). 
Campo de Criptana...»; y por la temprana vinculación entre éstos y el turismo, a través de la práctica de dedicar la estructura de algunos molinos sin uso a los países iberoamericanos, «el proyecto me parece espléndido. Un molino reconstruido por cada nación hispanoamericana: un original y significante monumento a la raza y a su mejor intérprete». Tras Pabón, Rupert Croft-Cooke ${ }^{20}$ siguió la ruta del Quijote (1965): «Los pequeños molinos de viento de La Mancha tienen una belleza diferente y sólo han inspirado una escena de ficción; pero es una escena conocida de todas las naciones y de todas las generaciones». Por último atendemos a José Antonio Vizcaíno ${ }^{21}$ (1966): «El camino hacia la Mancha, desde la capital de España, es como un brazo largo y estirado que se escurre, mapa abajo, rebasando Ocaña, La Guardia, Tembleque y Madridejos, y Consuegra es el codo de ese brazo, el que lo impulsa e imprime movimiento, hasta lograr que se cuele en la provincia de Ciudad Real -la más manchega de todas- a través del boquete tentador de Puerto Lápice (...). Es Campo de Criptana un pueblo tan propiamente manchego, tan genuino, y a la vez, tan pintoresco y singular, que si no existiera habría que inventarlo».

\subsection{La Mancha como destino turístico en la planificación del Franquismo}

La Mancha como destino turístico no puede ser comparada con las privilegiadas zonas de costa o con aquellos núcleos que por ejemplo por su legado patrimonial, fueron objeto de atención por parte de la administración para ser dotados de las infraestructuras y de los equipamientos ${ }^{22}$ necesarios para recibir al turismo de masas. El protagonismo que iba adquiriendo el turismo a nivel nacional era recogido en los informes del Consejo Económico Sindical Nacional (1967) y también en los provinciales (1967) y regionales (1970), donde se constataba que el desarrollo económico de España alcanzado en la década de los sesenta había sido debido en gran parte al favorable desarrollo del turismo.

En cierto modo, La Mancha siguió siendo un lugar de paso entre Madrid y Andalucía con un «ínfimo impacto del boom turístico» (Pardo, 2003: 224), pero existieron algunas iniciativas que pueden indicar un cambio en esta tendencia. En 1966 el Ministerio de Información y Turismo en estrecha colaboración con las Agencias de Viaje comenzó la puesta a punto e inauguración de la Ruta Cervantina fundamentada en las tierras que fueron escenario de la inmortal obra quijotesca, que por sí misma ya constituye un poderoso motivo de atracción para todos los lectores. El Consejo Económico Sindical Provincial afirmaba que La Mancha era de Cervantes «porque él le ha dado categoría universal, haciendo nacer en ella los personajes inmortales de su obra» y en relación a la Ruta Cervantina y/o la Ruta de Don Quijote, que adentrarse por los caminos y pueblos de La Mancha era una aventura que no podría olvidarse.

20 Croft-Cooke, R. (1970): De la mano de Don Quijote. Un viaje a través de la España de ayer y de hoy.

21 Vizcaíno, J. A. (1966): Caminos de La Mancha.

22 Una interesante iniciativa fue la declaración de Centros y Zonas de Interés Turístico Nacional, mediante la Ley 197/1963, de 28 de diciembre, que afirmaba la existencia de amplias zonas dotadas de suficientes atractivos naturales para convertirse en turísticas, «cuyas posibilidades no están suficientemente desarrolladas, por diversas razones, entre las que sobresale, principalmente, la de la ausencia de una política de fomento que ordene, estimule o supla la iniciativa privada de una manera eficaz y facilite su adecuada explotación turística». 


\section{Figura 2 \\ MOLINOS EN CAMPO DE CRIPTANA}

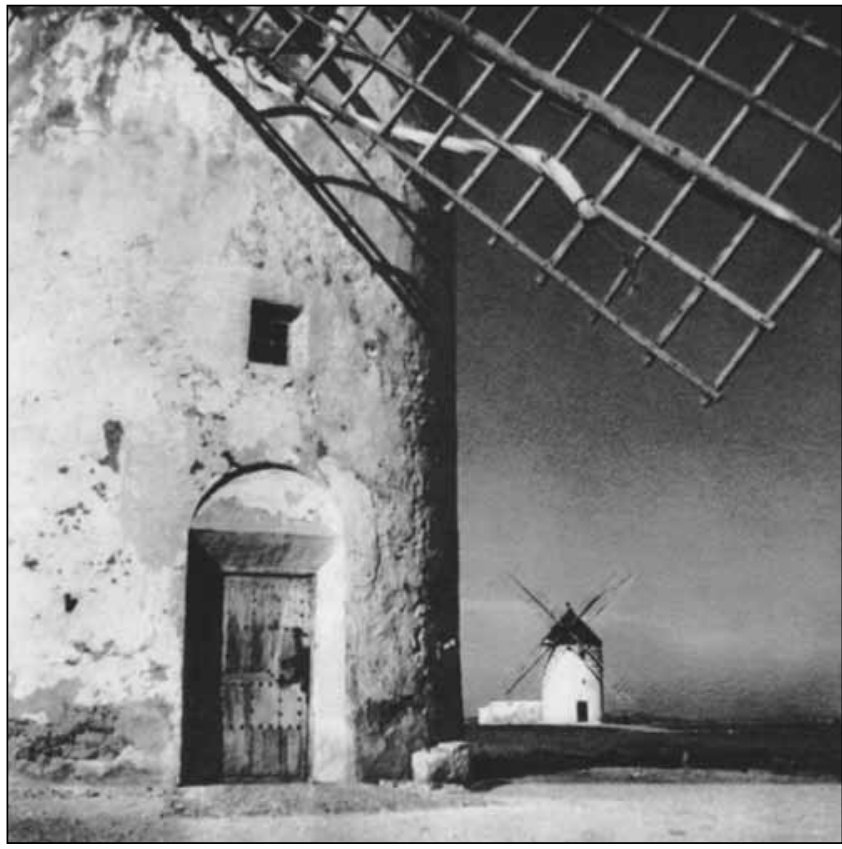

Fuente: Calleja Gutiérrez, R., 1957.

A mediados de los años sesenta del siglo XX, se hablará más intensamente de La Mancha debido al «Plan Ciudad Real» y a la anunciada inauguración de la «Ruta del Quijote», aunque «la cosa no pasaba de la edición de folletos anunciadores de la ruta y la declaración de buenas intenciones por parte de algunos cargos políticos», hecho que fue expuesto por el doctor Mora Solera a través del diario Lanza en 1965 cuando afirmaba sobre el «Plan Ciudad Real» que era «motivo para conocer lo que ya parecía olvidado» (Almarcha y Sánchez, 2005: 10). Así, en 1967, y en relación al II Plan de Desarrollo, se declaraba que entre los retos más importantes que se debían afrontar en la provincia de Ciudad Real estaban la mejora de las infraestructuras, que impulsara la creación de alojamientos en puntos singulares de la Ruta Cervantina, Fuencaliente, y Zonas Noroeste y Suroeste de la provincia, necesitadas de una promoción turística que revalorizase sus bellezas paisajísticas, y que además sería necesaria a lo largo de la carretera general Madrid-Cádiz desde Puerto Lápice a Venta de Cárdenas, la vía de enlace entre la capital y Andalucía.

Ese mismo año, su homólogo provincial, también insistía en el papel de las infraestructuras y solicitaba la unificación de esfuerzos interprovinciales (Toledo, Cuenca y Albacete) para completar la seguridad de la red viaria de enlace de lugares cervantinos y quijotescos. A la que se unía la puesta a punto de rutas y lugares turísticos como «la conveniencia de colocar placas en los lugares cervantinos extraídos del propio texto (...), 
Figura 3

PUBLICIDAD INSTALADA EN LA CARRETERA (Década de los 50 del siglo XX)

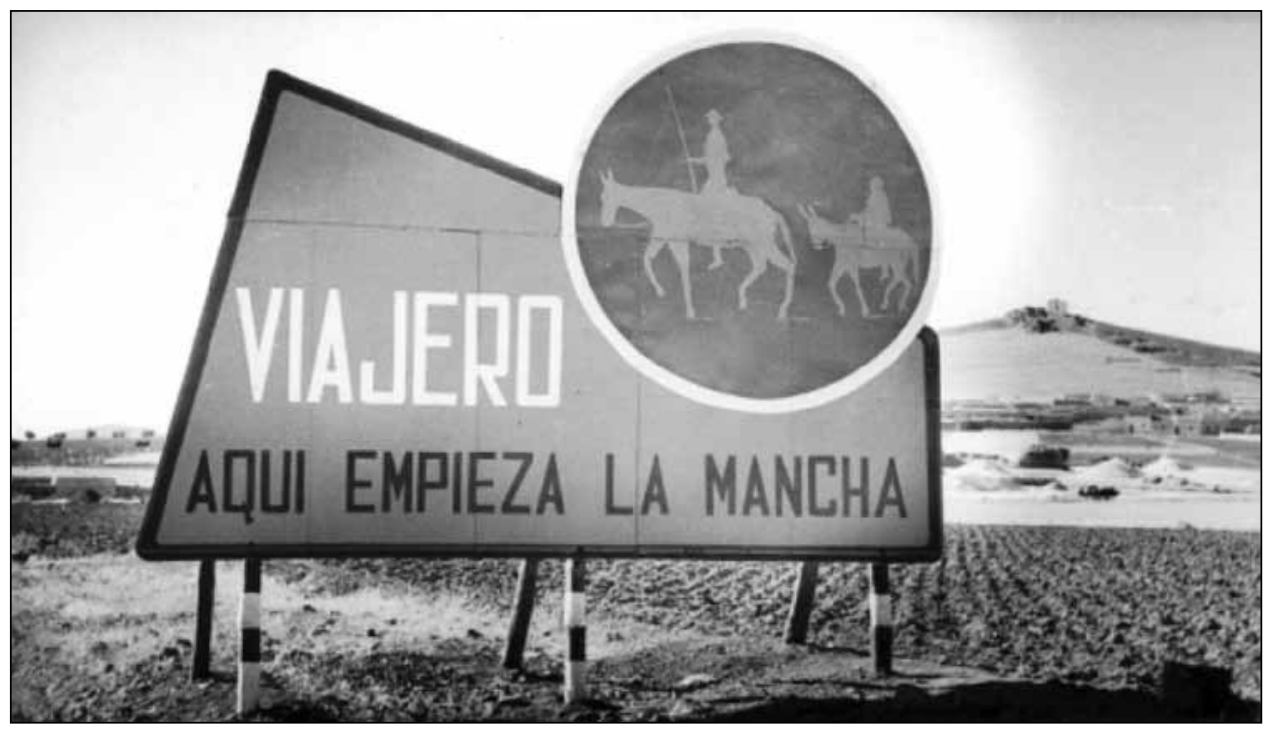

Fuente: Fotografía Herrera Piña. Hemeroteca del Centro de Estudios de Castilla-La Mancha, Universidad de Castilla-La Mancha.

detalle que estimarían mucho los turistas», la «creación de miradores de La Mancha» o la «Restauración de Monumentos y Ventas cervantinas famosas», como la Venta del Molinillo y la Venta del Alcalde, pues «sería de un enorme interés restaurar ambas ventas famosas y si posible fuera, reconstruir la Venta Tejada. La del Molinillo está mencionada en la novela de Cervantes Rinconete y Cortadillo; La Venta Tejada en la novela del mismo autor La Ilustre Fregona, y la del Alcalde en el lugar de acción de numerosos capítulos de Don Quijote de la Mancha. Se argumentaba que la restauración de las dos primeras ventas, no sería tarea difícil debido a la abundante bibliografía que existe sobre ellas, para devolverlas a sus tiempos de esplendor, no para explotarlas como tales, sino para visitarlas en su ambiente original. Las propuestas de restauración y reutilización del patrimonio arquitectónico llegaban también a elementos del patrimonio industrial agroalimentario, como los molinos de viento, para los que se proponía su reutilización como modalidad de alojamiento o vivienda ya que se constituirían como factor primordial de atracción turística (Amorós, 1975: 95).

Años después se celebró el V Pleno de la Comunidad Turística de La Mancha, en 1972, del que se hace eco el Diario La Vanguardia Española. En él se recogen nuevas propuestas turísticas como la celebración de una Semana Manchega en alguno de los grandes hoteles o almacenes de Madrid; impulsar la idea de airear el vino y el queso manchegos bajo la titulación genérica de la región, sin mengua de la peculiaridad de cada zona o insistir en la continuidad de los viajes de turistas norteamericanos, que iban por su segunda edición, enmarcados con el nombre de «La gran aventura de la Mancha». 


\section{Figura 4 \\ GRÁFICO DEL ITINERARIO}

\section{DEIEGACION PROVINCIAL DE INFORMACION Y TURISMO}

CIUDAD REAL

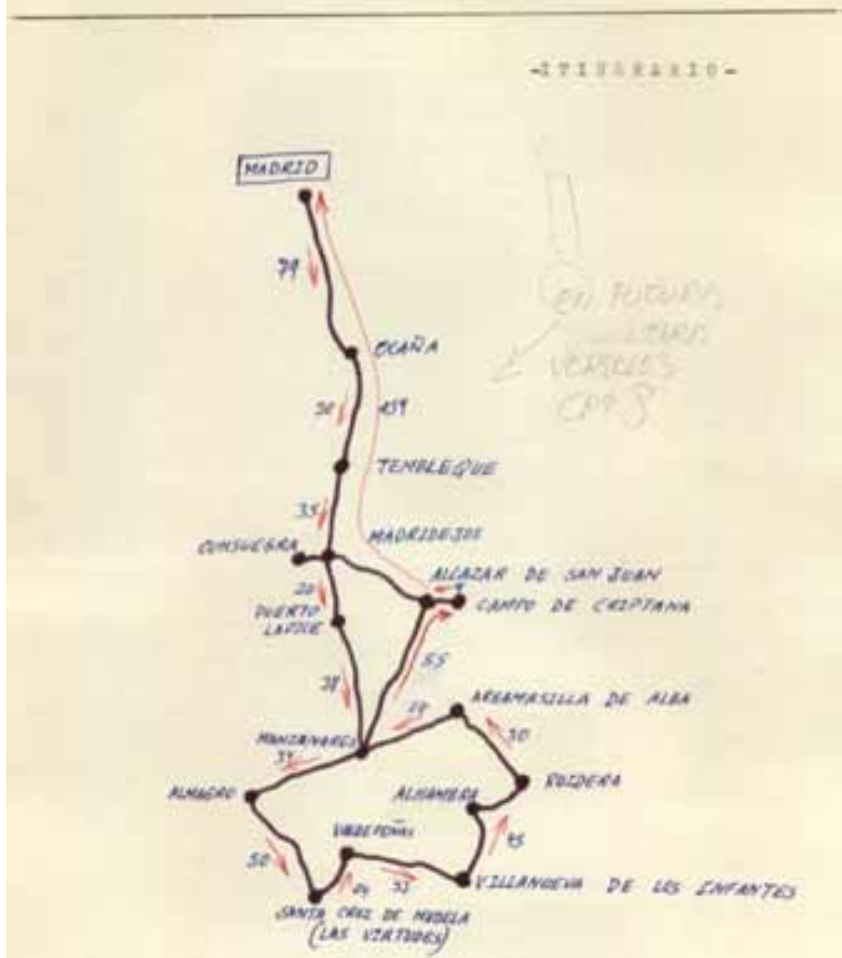

Fuente: Ministerio de Educación, Cultura y Deporte. Archivo General de la Administración, Fondo Ministerio de Información y Turismo, caja 59260.

\section{ITINERARIO POR LA MANCHA: «SUIZA EN LA AVENTURA DE LA MANCHA»}

Entre las múltiples iniciativas realizadas en esta época centra nuestra atención la promoción de La Mancha como destino turístico en Suiza, proyecto que se denominó «Suiza en la Aventura de La Mancha» ${ }^{23}$. Ya han pasado más de 40 años desde que un grupo de altos directivos suizos y germanos aterrizaran en el aeropuerto madrileño de Barajas, encaminados a conocer los recursos de la tierra de Don Quijote, a ser agasajados con todo tipo de detalles y que volvieran a su nación convencidos de que La Mancha podría formar parte de su oferta vacacional.

23 Ministerio de Educación, Cultura y Deporte. Archivo General de la Administración, Fondo Ministerio de Información y Turismo, caja 59260. 
Entre julio y agosto de 1972 comenzaron las conversaciones entre Francisco Pérez Naranjo, el Jefe de la Sección de Propaganda de la Dirección General de Promoción del Turismo de Madrid, y José Narváez Fernández, el delegado provincial de Información y Turismo de Ciudad Real para preparar la llegada de los expertos en turismo. La organización quedó a cargo de la Delegación Provincial de Información y Turismo de Ciudad Real y de las Líneas Aéreas Suizas «Swissair», representadas por los señores Redondo y Baldó, que actuaban de intérpretes de la expedición. La Dirección General de Promoción del Turismo de la Diputación Provincial lo patrocinaba y colaboraban la Agencia de Viajes Torremolinos S. A. y los Ayuntamientos de los municipios que serían los destinos de la visita: Ocaña, Tembleque, Consuegra, Almagro, Santa Cruz de Mudela, Valdepeñas, Villanueva de los Infantes, Argamasilla de Alba, Campo de Criptana y Alcázar de San Juan, además de los servicios hosteleros de la Venta del Quijote de Puerto Lápice, el Alberge Nacional de Manzanares y el Motel Meliá El Hidalgo de Valdepeñas.

En este proyecto se crea un itinerario (figura 4) para conocer La Mancha, que no fue definido como Ruta del Quijote, pero sí incorporó la visita a aquellos lugares que tradicionalmente se vinculan con la novela cervantina. Los destinos fueron seleccionados de acuerdo con una finalidad: el Régimen encumbraba aquellos lugares que de una forma $\mathrm{u}$ otra habían sido protagonistas bien sea a través de sus personajes, o de sus obras, de la Historia de España. La Mancha era entendida en este contexto como «una región natural de austeras bellezas, por cuyas llanuras infinitas cabalgó la castrense caballería religiosa de los «freires» combatientes en las batallas de la Reconquista; recorridas más tarde por el fabuloso Don Quijote a lomos de su fiel Rocinante en busca de las más sublimes aventuras ${ }^{24}$. Parajes, castillos, iglesias... eran valorados de acuerdo a esta finalidad y el Ministerio de Información y Turismo a través de su compleja estructura realizaba acciones de restauración y reconstrucción del patrimonio arquitectónico ya que se constituía como un poderoso reclamo en la atracción del turismo.

En la documentación consultada aparece la programación del itinerario en el que se establecen las horas aproximadas de llegada, los monumentos o parajes a visitar e incluso las vías de comunicación por las que transcurriría el recorrido. Un interesante proyecto en el que la administración se jugaba intereses turísticos nacionales, en este caso concretamente los de La Mancha, y que fue recogido por la prensa provincial (Diario Lanza ${ }^{25}$ y nacional (TVE) aportándonos interesante información y las imágenes de la expedición.

\subsection{Recorrido por La Mancha}

El itinerario comenzó el viernes 22 de septiembre de 1972 con la recogida de los expertos en el aeropuerto de Madrid-Barajas a las 15.30 horas, procedentes de Zurich en el vuelo SR 650, concluyéndose el domingo 24 cuando tomarían el vuelo SR 651 a las 16.00 horas para regresar a su país natal.

La primera parada estaba establecida en Ocaña para contemplar en la villa toledana la plaza y sus soportales. Ocaña cuenta con «nobles edificios, como la iglesia de San

24 Ibídem.

25 El enviado especial del diario Lanza fue el periodista Pedro Peral, que formó parte de la expedición. 
Pedro de estilo ojival, siglo XV, y el Convento de Carmelitas, donde está enterrado el poeta Alonso de Ercilla» ${ }^{26}$. La administración actuaba a través de diversos proyectos de intervención ${ }^{27}$ desde 1954 en la Plaza mayor de Ocaña, circunstancia que hacía que la visita a la villa constituyera una demostración ante los expertos en turismo de los logros alcanzados por el Estado de cara a la llegada del turismo, hecho que además permitiría la rentabilización de la inversión económica realizada. En Tembleque visitaron la Plaza porticada, en la que se venía actuando desde 1961, así como el templo parroquial. Unos meses después de la visita de los expertos fue declarada Conjunto Histórico-Artístico de carácter nacional a través del Decreto 445/1973 de 22 de febrero ${ }^{28}$. Seguidamente recorrieron la localidad de Consuegra donde la panorámica desde el cerro Calvario presidida por el castillo y sus afamados molinos levantó expresiones de admiración de todos los componentes de esta aventura, las explicaciones corrieron a cargo del teniente de alcalde y cronista de la villa, Francisco Domínguez. La visita terminó en el molino Mambrino, original museo mundial del botijo, desde el que se divisa una de las vistas más amplias del llano paisaje de la región. Consuegra ya contaba con un reconocido atractivo turístico, la administración actuó en el castillo desde 1964 a 1975, a lo que se une su registro por Orden del 9 de febrero de $1965^{29}$ como Denominación Geoturística con el slogan Mirador de La Mancha y Crestería Manchega para los parajes del cerro Calderico que dominan la ciudad.

La Venta de Don Quijote del municipio de Puerto Lápice sería el lugar designado para culminar la jornada, fueron recibidos por su director José Luis Legorburu. La Venta fue elegida por su historia ya que «fue primero Castillo del Foso y en él descansó el emperador Trajano. Cuando se convirtió en hospedería fue visitada por Santa Teresa de Jesús, por Don Juan de Austria, por Miguel de Cervantes...» ${ }^{30}$. El carácter manchego de sus instalaciones provocó el entusiasmo de los expedicionarios, conocedores de lo que puede constituir atractivo con vistas a una explotación comercial de esta Aventura en La Mancha. Aquí tuvo lugar la ceremonia de armar caballeros a los visitantes en la que fue nombrado, en representación del resto del grupo, Herr Kurt Huber de la compañía Swissair de Zurich. El señor Narváez pronunció en el acto unas palabras en relación al propósito de la expedición: «que conozcan nuestros recursos, para que después, profesionalmente, puedan organizar expediciones como la que hoy iniciamos por las literarias tierras de Don Quijote. Hemos pensado tanto las autoridades de turismo como las empresas y organismos colaboradores que os gustará el contraste entre vuestro país tecnificado y con alto nivel de vida, con estos lugares de la España auténtica de nuestras provincias interiores» ${ }^{31}$. La jornada concluyó en Manzanares para pernoctar en

26 Ministerio de Educación, Cultura y Deporte. Archivo General de la Administración, Fondo Ministerio de Información y Turismo, caja 59260.

27 Entenderemos como proyectos de intervención, de forma genérica, los proyectos de restauración, de ordenación, de obras, etc., sobre diversos monumentos o conjuntos monumentales por parte de la administración del Régimen.

28 BOE, 13-03-1973.

29 BOE, 25-02-1965.

30 Ministerio de Educación, Cultura y Deporte. Archivo General de la Administración, Fondo Ministerio de Información y Turismo, caja 59260.

31 Lanza, 23-09-1972. 


\section{Figura 5 \\ LA EXPEDICIÓN CONTEMPLANDO LOS MOLINOS DE CONSUEGRA (TOLEDO)}

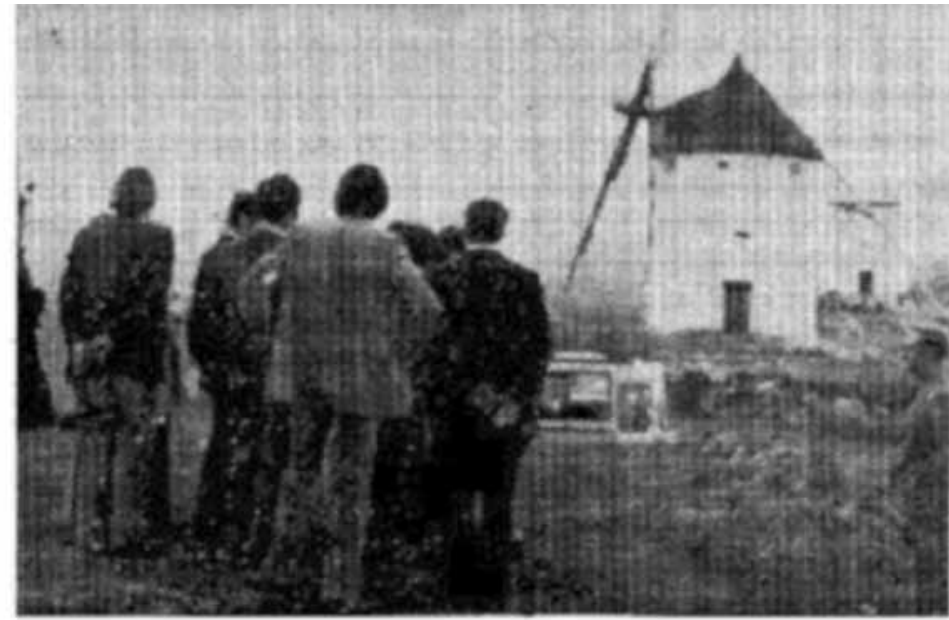

Fuente: http://ceclmdigital2.uclm.es/hemeroteca/cgi-bin/Pandora

Figura 6

CEREMONIA DE ARMAR CABALLEROS A LOS VISITANTES
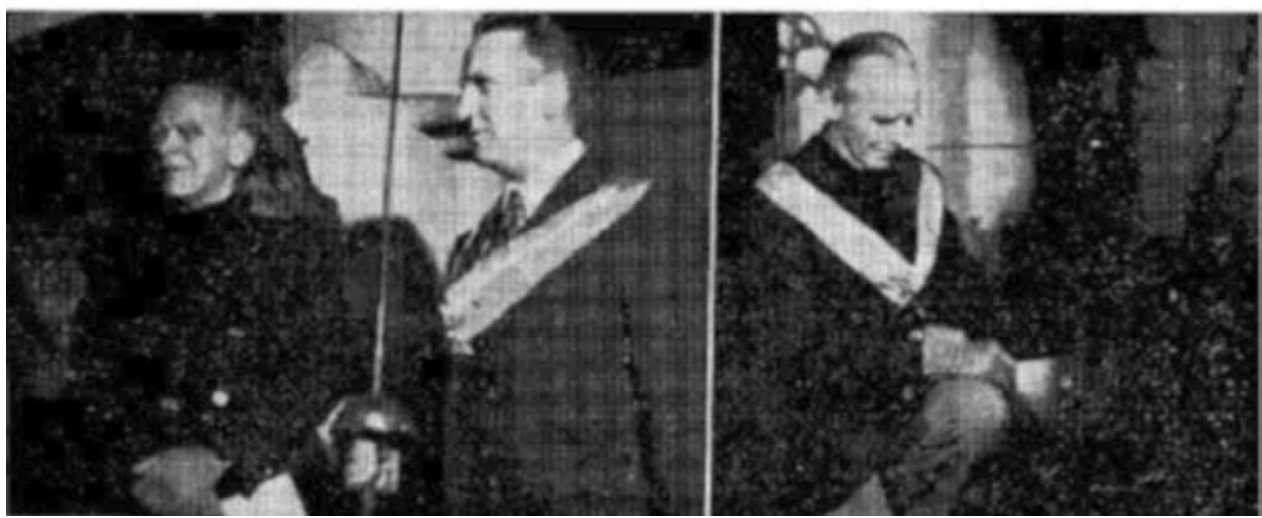

Fuente: http://ceclmdigital2.uclm.es/hemeroteca/cgi-bin/Pandora

el Albergue Nacional de Turismo. Éste fue uno de los primeros albergues de la Red de Albergues de Carreteras integrada por la Junta de Paradores y Hosterías. Comenzó su actividad en 1932 y se construyó en el kilómetro 175 de la Carretera de Madrid a Cádiz. En 1980, tras 14 meses de inactividad, se convirtió en el Parador de Manzanares ${ }^{32}$.

32 <http://www.parador.es/recursos/doc/Corporativo/Area_de_prensa/Notas_de_prensa/2008/711237922_ 24112008131716.pdf> 75 años del Parador de Manzanares. 
El sábado 23 de septiembre comenzó el itinerario en Almagro, denominada capital del Campo de Calatrava y uno de los puntos más importantes de la Aventura manchega. Visitaron la Plaza y el Corral de Comedias, así como su popular industria de encajes, «diez mil encajeras tejen el encaje de bolillos conocido universalmente como encaje de Almagro, realizando verdaderos primores en mantillas y paños ${ }^{33}$. El Corral de Comedias (Monumento histórico-artístico desde 1955), y la Plaza Mayor porticada ya eran importantes monumentos sobre los que la administración trabajaba con interés pues existen proyectos de intervención desde 1954. Además solo unos meses antes de la visita de los agentes suizos, el 13 de julio de 1972 se declaraba el núcleo mediante el Decreto 2104/1972 ${ }^{34}$ Conjunto Histórico-Artístico. Disfrutaron de Almagro recorriendo sus rincones, la calle de las Bernardas, la oficina de información turística, la riqueza heráldica, etc., la prensa recogía sus impresiones: ««Esto esto», repetían una y otra vez quienes pueden hacer venir, como organizadores de rutas y excursiones, a muchos miles de visitantes centroeuropeos» (...) Los expertos buscaban en Almagro el «ruralismo aseado, tipismo autentico, conservación y rescate de monumentos, sosiego, paz, andar por las calles sin miedo a ser atropellado, encontrarse al torcer una esquina con una encajera sentada en una silla de enea, jugando al juego de los bolillos» ${ }^{35}$. Todo un conjunto de elementos, de recursos, que caracterizan culturalmente a La Mancha, y que en la actualidad siguen siendo reclamo turístico de esta comarca y de la región.

En Santa Cruz de Mudela visitaron el Santuario Mariano de Las Virtudes situado a unos 6 kilómetros. El edificio del siglo XVII destaca por su «techumbre mudéjar y pinturas en la cúpula del siglo XVIII ${ }^{36}$. Más interesante si aún cabe es la Plaza de Toros anexa y «considerada como la más antigua de España de estructura cuadrada y de construcción muy similar al Corral de Comedias de Almagro» ${ }^{37}$. En ella disfrutaron de un Festejo Taurino como ilustran las instantáneas (figura 7). Posteriormente se desplazaron hasta Valdepeñas, donde se interesaron por la arquitectura de sus edificios, la iglesia de la Asunción, o el mayor molino de viento de España levantado para museo-exposición del pintor local Gregorio Prieto. En esta ciudad famosa por sus caldos y enormes bodegas, conocidas como «Las catedrales del vino», se visitó la Cooperativa La Invencible, la primera cooperativa vitivinícola creada durante la Dictadura, un icono de la labor del Régimen, y que en la actualidad está siendo en parte demolida. El posterior almuerzo tuvo lugar en el Motel Meliá «El Hidalgo».

El comienzo de la tarde tuvo a Villanueva de los Infantes como protagonista, municipio que destaca por su rica historia y la de sus personajes. «Enclavada en el histórico Campo de Montiel debe su nombre al Infante D. Enrique -Maestre de Santiago- y sus hermanos D. Alfonso, D. Juan y D. Pedro» ${ }^{38}$. En la villa realizaron un recorrido monumental por la Plaza Mayor, la Iglesia de San Andrés Apóstol, la Casa Rectoral, el Hospital del

33 Ministerio de Educación, Cultura y Deporte. Archivo General de la Administración, Fondo Ministerio de Información y Turismo, caja 59260.

34 BOE, 01-08-1972.

35 Lanza, 24-09-1972

36 Ministerio de Educación, Cultura y Deporte. Archivo General de la Administración, Fondo Ministerio de Información y Turismo, caja 59260.

37 Ibídem.

38 Ibídem. 


\section{PLAZA DE TOROS DE LAS VIRTUDES}

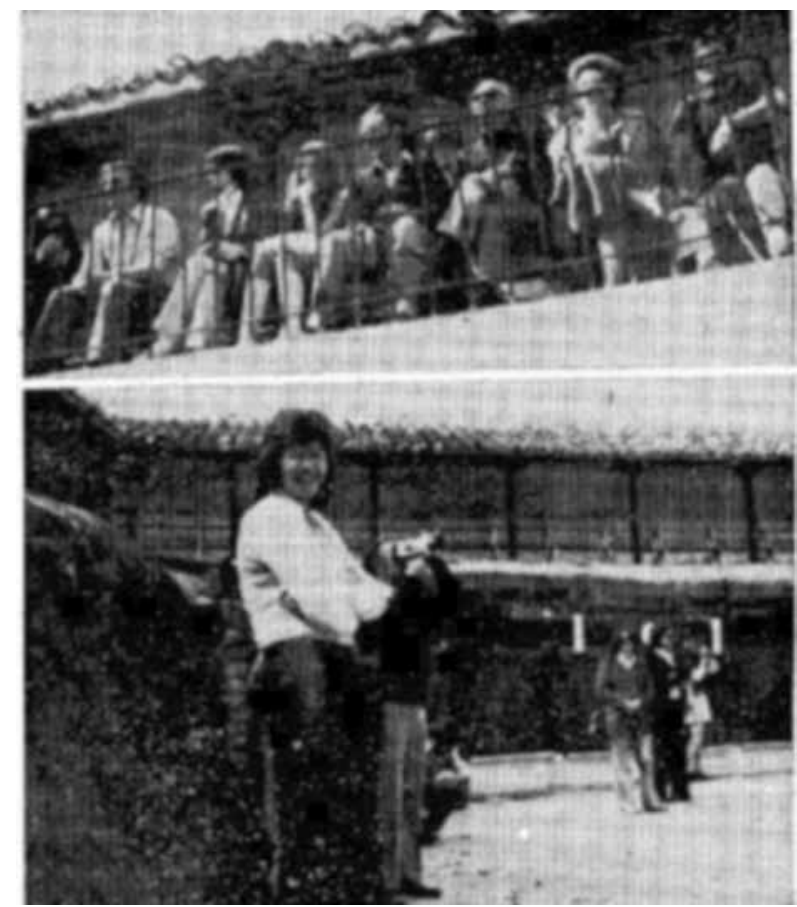

Fuente: http://ceclmdigital2.uclm.es/hemeroteca/cgi-bin/Pandora

Remedio... aunque sin duda fue el Convento de Santo Domingo el que hizo que todos guardaran silencio al contemplar la última morada de Francisco de Quevedo; y en la que «hay que penetrar en sus jardines, en sus casas con escudos nobiliarios, contemplar el bosque de torres... la Cruz de Santiago repitiéndose por doquier para ver que estas en la ciudad museo, santuario místico «hortus clausus de la Mancha»» ${ }^{39}$. Dos años después de la visita, mediante el Decreto 3708/1974 de 20 de diciembre ${ }^{40}$, se declaró Conjunto Histórico-Artístico la ciudad de Villanueva de los Infantes, culmen de unas intervenciones en la villa que se sucedían desde 1961.

Las Lagunas de Ruidera (actual Parque Natural de las Lagunas de Ruidera) no podían faltar en el itinerario. Fueron recibidos en el establecimiento «Entrelagos» por Juan Ramón García-Noblejas, realizaron un breve descanso con el tiempo suficiente para su contemplación y descubrir este «paisaje inesperado de auténtica sorpresa para el viajero» ${ }^{41}$, en el que los expertos en turismo pusieron de manifiesto el potencial de las Lagunas como destino

\footnotetext{
39 Ibídem.

40 BOE, 31-01-1975.

41 Ministerio de Educación, Cultura y Deporte. Archivo General de la Administración, Fondo Ministerio de Información y Turismo, caja 59260.
} 


\section{Figura 8 \\ PASEO POR LA LAGUNA COLGADA (Lagunas de Ruidera)}

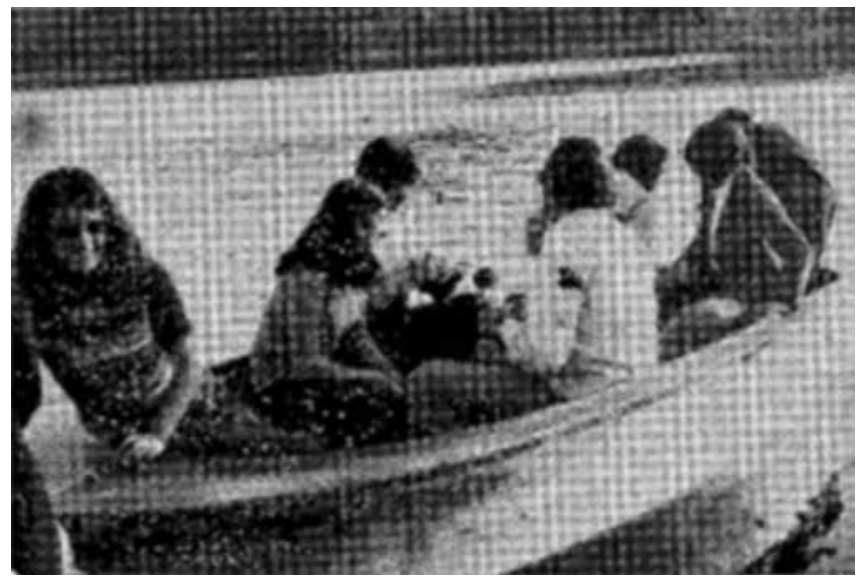

Fuente: http://ceclmdigital2.uclm.es/hemeroteca/cgi-bin/Pandora

turístico, espacio idóneo en el que veranear. Ruth Lissi, jefe de promoción y ventas de la «Jets Tour» señaló la idoneidad de las Lagunas como lugar de descanso para aquellas personas de negocios que buscan la tranquilidad, y que con las infraestructuras adecuadas se convertiría en «epicentro residencial» ${ }^{42}$.

En Argamasilla de Alba se vería la Cueva de Medrano que la tradición identifica con la prisión de Cervantes, cueva que solo un mes después de la visita de los expertos fue declara Monumento Histórico-Artístico Nacional mediante el Decreto 3147/1972 de 26 de octubre ${ }^{43}$, y la Casa de Sansón Carrasco. «Aquí está la rebotica en la que se reunían los Académicos, la casa de don Quijote y la del bachiller Sansón Carrasco, y en la iglesia de San Juan Bautista el cuadro exvoto de don Rodrigo Pacheco, en el que no pocos identifican a don Quijote de la Mancha» ${ }^{44}$. El municipio ya contaba con un interesante potencial por su cercanía al embalse de Peñarroya, al castillo y al santuario mariano de análogo nombre de sus inmediaciones, que se encuentran en uno de los pasos obligados a las Lagunas de Ruidera, motivo que propició su atención por parte de la administración. A pesar de todo la visita a Argamasilla no fue la deseada según deja ver una nota de prensa ${ }^{45}$, ya que la expedición no quedó contenta con el recibimiento en el pueblo, algo que fue contestado, argumentado y justificado a través del mismo diario enérgicamente por el señor Serrano. La jornada concluyó con el regreso al Albergue Nacional de Turismo de Manzanares.

42 Lanza, 04-10-1972

43 BOE, 16-11-1972.

44 Ministerio de Educación, Cultura y Deporte. Archivo General de la Administración, Fondo Ministerio de Información y Turismo, caja 59260.

45 Lanza, 24-09-1972 


\section{Figura 9 \\ LA EXPEDICIÓN EN CAMPO DE CRIPTANA}
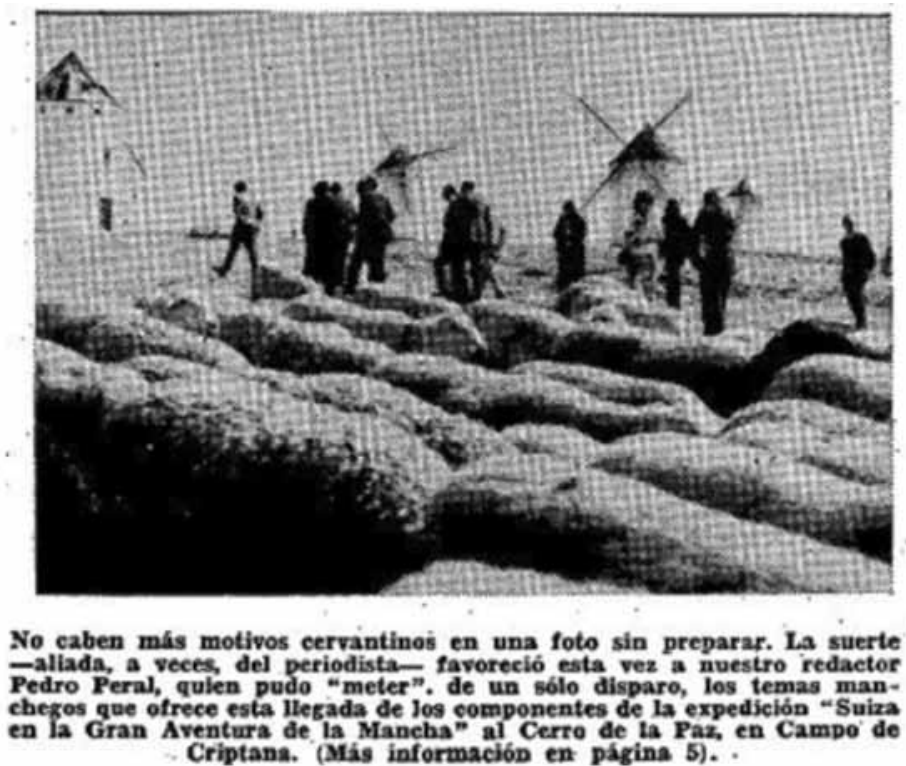

Fuente: http://ceclmdigital2.uclm.es/hemeroteca/cgi-bin/Pandora

El domingo 24 de septiembre fue el último día del itinerario. Comenzó oyendo la santa misa en el Alberge Nacional, para posteriormente tomar el desayuno y dar inicio a la expedición. En Campo de Criptana fueron recibidos por el Alcalde, Antonio López Casero, el teniente de alcalde, Cabañero y miembros de la Junta del Centro de Iniciativas y Turismo, encabezados por su presidente Vicente Rodríguez. Aquí visitaron sus famosos molinos, «Criptana - ha escrito Walter Starkie - es el sitio más acogedor de toda la Mancha». Un blanquísimo caserío, sol radiante y en el cerro la serie de molinos más interesante de toda la región. Porque los países iberoamericanos rivalizan en levantar en este sitio molinos en homenaje al autor del Quijote» ${ }^{46}$. Los molinos impresionaron a los visitantes que no pararon de fotografiarlos para su álbum de recuerdos como para la memoria-informe que cada experto debía hacer a la dirección de su agencia. A pesar del retraso que llevaba la expedición, hubo tiempo para ver la maquinaria auténtica de un molino, Francisco Cifuentes, experimentado molinero les descubrió y explicó los pormenores del oficio y de la interesante arquitectura molinera, donde tomaron un aperitivo presentado y servido dentro del molino «Cariari» de Costa Rica.${ }^{47}$ En la expedición no se obviaron las dificultades de conservación y mantenimiento de estos edificios. El papel que adquieren como elemento configurador del imaginario cervantino

46 Ministerio de Educación, Cultura y Deporte. Archivo General de la Administración, Fondo Ministerio de Información y Turismo, caja 59260.

47 Lanza, 26-09-1972 
propició que por Real Decreto 3322/1978 de 7 de diciembre ${ }^{48}$ se declararan Monumento Histórico-Artístico los molinos de viento Burleta, Sardinero e Infanto.

Por último, Alcázar de San Juan fue el núcleo elegido para finalizar la expedición, importante centro de servicios por su posición estratégica, como refleja su Denominación Geoturística, Alcázar de San Juan Corazón de la Mancha registrada para su conjunto urbano por Orden del 11 julio de $1966^{49}$, de la que hacía mención su abundante señalización «Corazón de la Mancha». Fueron recibidos en el ayuntamiento por el alcalde Eugenio Molina y los concejales Rubio, Cabanas y Casero Abengózar, siendo éste último el que realizó las explicaciones del recorrido monumental. Visitaron algunos de los monumentos más significativos como la Iglesia de Santa María, el Torreón del Palacio del Gran Prior, intervenidos por la administración a partir de sendos proyectos de restauración ${ }^{50}$, Museo Arqueológico Fray Juan Cobo, Iglesia de la Santísima Trinidad... así como un Festival Folclórico Nacional, etc. Visitaron la finca de «La Platera» donde disfrutaron de una comida manchega, y recibieron el diploma de visita acreditativo de haberse sentado en la silla de la amistad sanchopancesca. Para concluir, el alcalde protagonizó unas palabras de despedida a la expedición cuyo próximo destino era el aeropuerto, con las que expresó su deseo de que les gustará «a los que amamos La Mancha sin beneficio material que hayan vivido ustedes La Mancha auténtica con su trabajo y sus gentes, porque La Mancha es algo muy distinto de la clásica España de pandereta; es cosa muy seria» (...). Los expedicionarios, en palabras del señor Huber, expresaron el agradecimiento por la cortesía y hospitalidad recibida en el viaje, y destacaron la labor del señor Narváez; Se que «La Mancha ofrece grandes posibilidades turísticas, sobre todo para grupos pequeños y de gente madura. España, a la que reconozco su primacía en Europa, tiene otros muchos alicientes para los centro-europeos, aparte de sus costas» y en los informes a sus «superiores señalarán las indudables posibilidades que ofrece la provincia cara al turismo del futuro más inmediato» ${ }^{51}$.

\section{BREVES CONCLUSIONES}

«Suiza en la Aventura de la Mancha» constituye un interesante referente para el análisis de los orígenes del turismo cultural en nuestra región, en este caso protagonizado por un grupo de directivos turísticos extranjeros. El proyecto que dio a conocer las peculiaridades La Mancha en un fin de semana, estuvo repleto de los tipismos que siguen imperando en la actualidad, (paisajes agrarios, escasa industrialización, fiestas, folklore...). El relativo subdesarrollo de España, el de sus territorios rurales, no fue visto como una debilidad, sino como una oportunidad para que el turista conociera unas tradiciones arraigadas a la tierra. Dejando atrás las inexactitudes de carácter geográfico sobre La Mancha, el itinerario puso de manifiesto los recursos territoriales de la comarca que en los años setenta fueron utilizados como reclamo turístico, desde los molinos de viento convertidos en protagonistas del paisaje manchego, hasta la historia, la cultura o la gastronomía popular, todo ello

48 BOE, 03-02-1979.

49 BOE, 04-08-1966.

50 Véase Almarcha, E., 2012.

51 Lanza, 26-09-1972 
en íntima relación con la figura de El Quijote, en un proceso de internacionalización del producto turístico español apoyado en una de las grandes obras de la literatura.

La progresiva afluencia de un turismo de masas centrado en las costas, en el sol y playa, que comenzaba a buscar nuevos destinos culturales en el interior, hizo que el Estado pusiera en funcionamiento diferentes mecanismos en todo el territorio para potenciar los destinos turísticos, es el caso de las Denominaciones Geoturísticas, de los Centros y Zonas de Interés Turístico Nacional, de las Fiestas de Interés Turístico, etc., que se desarrollaron paralelamente a otras medidas encaminadas a la protección y preservación de nuestro patrimonio como los Conjuntos Histórico-Artísticos. Todo este entramado de «figuras administrativas» del franquismo generó unas interesantes conexiones entre el turismo y el patrimonio, en un contexto en el que los intereses económicos empezaban a entrar en contraposición con la conservación patrimonial. Se sucedían proyectos de intervención (restauraciones, reconstrucciones, etc.) de elementos del patrimonio histórico-artístico, cuidadosamente escogidos, para su «reutilización»y «puesta en valor» de cara a formar parte de los recursos de atracción turística.

En el proyecto expuesto quedan representadas a través de diversas acciones en las localidades visitadas, hacemos referencia a proyectos de intervención y/o declaraciones de diversa índole, como las realizadas unos meses después de la vista de los expertos en turismo, de la plaza Mayor de Tembleque o de la Cueva de Medrano de Argamasilla de Alba como Conjunto Histórico-Artístico o, la visita a dos localidades con importantes recursos vinculados al quijotismo y a La Mancha, donde el Estado ya trabajaba en su promoción turística través de la declaración de Denominaciones Geoturísticas, la de Consuegra Mirador de La Mancha y Crestería Manchega y la de Alcázar de San Juan, Alcázar de San Juan Corazón de la Mancha. En resumen, se buscaba la mejora de las infraestructuras, el acondicionamiento de espacios y miradores que permitieran la visualización del paisaje manchego, la restauración de elementos arquitectónicos vinculados a la novela cervantina, etc., actuaciones encaminadas a la promoción del turismo cultural por medio de un itinerario que pudo servir de espaldarazo final a las labores del Régimen en esta región, y que serían rentabilizadas con la llegada de divisas extranjeras a La Mancha.

\section{BIBLIOGRAFÍA}

ALMARCHA NÚÑEZ-HERRADOR, E. (2001): «La imagen de los molinos de viento en la literatura de viajeros extranjeros por España», en Los molinos de viento (Actas del I Congreso Internacional). Alcázar de San Juan, Patronato Municipal de Cultura, pp. 35-43.

ALMARCHA NÚÑEZ-HERRADOR, E. y SÁNCHEZ, SÁNCHEZ, I. (2005): La ruta de Don Quijote/Azorín, I Centenario 1905-2005. Ciudad Real, Universidad de Castilla-La Mancha y Centro de Estudios de Castilla-La Mancha.

ALMARCHA NÚÑEZ-HERRADOR, E. (2012): «La restauración del patrimonio monumental de los Hospitalarios durante el franquismo en Alcázar de San Juan (Ciudad Real)», en RINCÓN, I., IZQUIERDO, M., PASCUAL, A. (Eds.): I Simposium Patrimonio Artístico de la Orden de San Juan de Jerusalén en España. Zaragoza, Aneto Publicaciones, pp. 303-316. 
ALMEIDA GARCÍA, F. (2012): «La política turística en España y Portugal», Cuadernos de Turismo, n. 30, pp. 9-34.

AMORÓS DUPUY, S. (1975): «El molino manchego como factor de atracción turística», Estudios Turísticos, n. 46, pp. 95-97.

ARRILLAGA SÁNCHEZ, J. I. DE (2005): «Primeras experiencias 1950-1962», en BAYÓN, F. (Dir.): 50 Años del turismo español. Un análisis histórico y estructural. Madrid, Centro de Estudios Ramón Areces S. A., pp. 45-70.

BAUTISTA NARANJO, E. (2010): Un americano en La Mancha tras las huellas de don Quijote. Ciudad Real, Centro de Estudios de Castilla-La Mancha, Universidad de Castilla-La Mancha.

BAYÓN MARINÉ, F. (Dir.) (2005): 50 Años del turismo español. Un análisis histórico y estructural. Madrid, Centro de Estudios Ramón Areces S. A. Disponible en http:// bibliotecadigitalhispanica.bne.es///exlibris/dtl/d3_1/apache_media/L2V4bGlicmlzL2R0bC9kM18xL2FwYWNoZV9tZWRpYS8xODEzNjQ4.pdf

CALLEJA GUTIÉRREZ, R. (1957): Nueva apología turística de España. Madrid, Publicaciones de la Dirección General del Turismo.

CAMPOS ROMERO, M.L. (Coord.) (2002): El turismo en Castilla-La Mancha. Análisis y prospectiva. Cuenca, Ediciones de la Universidad de Castilla-La Mancha.

CAMPOS ROMERO, M. L. (2006): «La explotación de la figura literaria del Quijote como recurso turístico», en PILLET CAPDEPÓN, F. y PLAZA TABASCO, J. (Coord.): El espacio geográfico del Quijote en Castilla-La Mancha. Cuenca, Ediciones de la Universidad de Castilla-La Mancha, pp. 275-283.

CAÑIZARES RUÍZ, M.C. (2008): «La «Ruta de Don Quijote» en Castilla-La Mancha (España): nuevo Itinerario Cultural Europeo », Nimbus, n. 21-22, pp. 55-75.

CAÑIZARES RUÍZ, M.C. (2009): «Molinos reales, molinos imaginarios, molinos inventados: la revalorización de un patrimonio singular en La Mancha», en V Congreso Internacional de Molinología. Toledo, Empresa Pública Don Quijote de la Mancha 2005, pp. 277-285.

CAÑIZARES RUÍZ, M.C. (2011): «El territorio como protagonista en el análisis geográfico del patrimonio industrial», en VV.AA.: I Congreso Internacional de Investigación sobre Paisaje Industrial. Sevilla, ETSA, p. 1-7.

CONSEJO ECONÓMICO SINDICAL NACIONAL (1967): Las provincias ante el II Plan de Desarrollo. Madrid.

CONSEJO ECONÓMICO SINDICAL PROVINCIAL (1967): Ponencias del IV Pleno del Consejo Económico Sindical Provincial de Ciudad Real. Madrid.

CONSEJO ECONÓMICO SINDICAL INTERPROVINCIAL DE LA MANCHA (1970): Estudios sobre las posibilidades del desarrollo socioeconómico de la Mancha. Madrid.

CROFT-COOKE, R. (1970): De la mano de Don Quijote. Un viaje a través de la España de ayer y de hoy. Barcelona, Plaza \& Janes S.A.

DAVILLIER, C., Y DORE, G. (1868): «Voyage en Espagne. La Manche», en Le Tour du Monde, Deuxieme semestre, Tomo XVIII, pp. 289-304.

DÍEZ. E. et al. (1995): Viaje a La Mancha en 1774 / José de Viera y Clavijo. Almagro, Taller de Edición Escolar del INB «Clavero Fernández de Córdoba». 
DUCHESSE DE ABRANTÈS (1837): Souvenirs d'une ambassade et d'un séjour en Espagne et en Portugal de 1808 à 1811. Paris, Ollivier Libraire-Éditeur. Disponible en http://gallica.bnf.fr/ark:/12148/bpt6k65670326.r=.langES

FERNÁNDEZ FÚSTER, L. (1991): Historia general del turismo de masas. Madrid, Alianza.

FORD, R. (1982): Manual para viajeros por España y lectores en casa. Observaciones generales. Madrid, Editorial Turner.

GARCÍA MARCHANTE, J.S. y FERNÁNDEZ FERNÁNDEZ, M.C. (2000): El espacio del Quijote: el paisaje de La Mancha. Cuenca, Universidad de Castilla-La Mancha.

GARCÍA MARTÍNEZ, C. (2006): «Luz, color y horizonte: imagen del paisaje de La Mancha en la pintura», en PILLET CAPDEPÓN, F. y PLAZA TABASCO, J. (Coord.): El espacio geográfico del Quijote en Castilla-La Mancha. Cuenca, Ediciones de la Universidad de Castilla-La Mancha, pp. 275-283.

GIMÉNEZ SERRANO, J. (1848): «Un paseo a la patria de Don Quijote», en Semanario Pintoresco Español, $\mathrm{n}^{\circ}$ 16, pp. 19-24.

GONZÁLEZ CUENCA, J. et al. (2003): Paisajes y rutas del Quijote. Toledo, Junta de Comunidades de Castilla-La Mancha.

JACCACI, A. F. (1897): On the trail of Don Quixote: being a record of rambles in the ancient province of La Mancha. Illustrated by Daniel Vierge. London, Lawrence and Bullen.

LARRETA, J. y PRIETO, F. (1923): La vuelta a la Mancha a pié. Valdepeñas. Talleres gráficos La Región.

LOCKER, E. H. (1848): Views in Spain. London, John Murray.

MILFORD, J. (1816): Peninsular Sketches, during a Recent Tour. London, John Richardson/J. Hatchard.

MORENO GARRIDO, A. (2007): Historia del Turismo en España en el siglo XX. Madrid, Síntesis.

MORENO GARRIDO, A. (2011): «Fuentes para una historia del turismo español. Fondos documentales del Archivo General de la Administración», en X Congreso Internacional de la AEHE. Sevilla, Universidad Pablo Olavide, pp. 1-17.

ORTAS DURAND, E. (2006): Leer el camino. Cervantes y el «Quijote» en los viajeros extranjeros por España (1701-1846). Alcalá de Henares, Centro de Estudios Cervantinos.

PABÓN NÚÑEZ, L. (1962): Por La Mancha de Cervantes y Quevedo. Madrid, Ediciones Hipanolusoamericanas.

PANADERO MOYA, M. (2011): «Los grandes sistemas paisajísticos», en PONS GINER, B. (Dir.): Atlas de los paisajes de Castilla-La Mancha. Ciudad Real, Ediciones de la Universidad de Castilla-La Mancha, pp. 23-28.

PANADERO MOYA, M. y PILLET CAPDEPÓN, F. (2011): «Las comarcas geográficas de Castilla-La Mancha», en PONS GINER, B. (Dir.): Atlas de los paisajes de CastillaLa Mancha. Ciudad Real, Ediciones de la Universidad de Castilla-La Mancha, pp. 22-44.

PARDO PARDO, M.R. (2003): «La economía durante el franquismo», en REQUENA GALLEGO, M. (Coord.) Castilla-La Mancha en el franquismo. Ciudad Real, Biblioteca Añil, pp. 173-224. 
PELLEJERO MARTÍNEZ, C. (Dir.) (1999): Historia de la economía del turismo. Madrid, Civitas.

PELLEJERO MARTÍNEZ, C. (2000): La intervención del estado en el sector turístico. De la Comisión Nacional a la empresa de turismo. Sevilla, Junta de Andalucía.

PEINADO MARTÍN-MONTALVO, M. et al. (2009): Itinerarios geográficos y paisajes por la provincia de Ciudad Real. Guía de salidas de campo del XXI Congreso de Geógrafos Españoles. Ciudad Real. Diputación de Ciudad Real.

PILLET CAPDEPÓN, F. (2001): La Mancha. Transformaciones de un espacio rural. Madrid, Celeste Ediciones.

PILLET CAPDEPÓN, F. (2002): «De la ficción a la percepción. Del Quijote a La Mancha literaria», en Boletín de la Asociación de Geógrafos Españoles, n. 34, pp. 147-157.

PILLET CAPDEPÓN, F. y PLAZA TABASCO, J. (Coord.) (2006): El espacio geográfico del Quijote en Castilla-La Mancha. Cuenca, Ediciones de la Universidad de CastillaLa Mancha.

PILLET CAPDEPÓN, F. (2006): «La imagen literaria de la Mancha desde la publicación del Quijote», en PILLET CAPDEPÓN, F. y PLAZA TABASCO, J. (Coord.): El espacio geográfico del Quijote en Castilla-La Mancha. Cuenca, Ediciones de la Universidad de Castilla-La Mancha, pp. 35-60.

PILLET CAPDEPÓN, F. (2010): «La diversidad geográfica de Castilla-La Mancha: la comarcalización geográfica y sus municipios», en CEBRIÁN, F., PILLET, F. y CARPIO, J. (Coord.): Las escalas de la geografía: del mundo al lugar. Homenaje al profesor Miguel Panadero Moya. Cuenca, Universidad de Castilla-La Mancha, pp. 25-48.

PILLET CAPDEPÓN, F. (2011): «El turismo de interior y el patrimonio territorial en Castilla-La Mancha», Cuadernos de Turismo, n. 27, pp. 725-741.

PILLET CAPDEPÓN, F. (2012): «El turismo de interior en la España peninsular: el patrimonio territorial como destino turístico», Boletín de la Asociación de Geógrafos Españoles, n. 59, pp. 345-366.

PONZ PIQUER, A. (1972): Viage de España: en que se da noticia de las cosas más apreciables y dignas de saberse, que hay en ella. Madrid, Atlas, Tomo XVI.

PUCHE, R., SERRANO, M. y DÍEZ, J. (2004): Guía de viaje por la ruta de Don Quijote. Itinerarios, monumentos, gastronomía y folclore. Barcelona, Belacqua.

RUÍZ PULPÓN, A.R. (2013): «El viñedo en espaldera: nueva realidad en los paisajes vitivinícolas de Castilla-La Mancha», en Boletín de la Asociación de Geógrafos Españoles, n. 26, pp. 240-270.

SÁNCHEZ RIVERO, A. y MARIUTTI, A. (1933): Viaje de Cosme de Médicis por España y Portugal: (1668-1669). Madrid, Junta de Ampliación de Estudios e Investigaciones Científicas. Centro de Estudios Históricos.

SÁNCHEZ SÁNCHEZ, E.M. (2001): «El auge del turismo europeo en la España de los años sesenta», en Arbor, n. 669, pp. 201-224.

SASHA PACK. D. (2009): La invasión pacífica: los turistas y la España de Franco. Madrid, Turner.

TOWNSEND, J. (1988): Viaje por España en la época de Carlos III (1786 y 1787). Madrid, Editorial Turner 
UNCETA SATRÚSTEGUI, M. (Coord.) (2004): Ruta de Don Quijote a pie en bicicleta o a caballo. Madrid, El País Aguilar, Santillana Ediciones Generales S. L.

VALLEJO POUSADA, R. (2013): «Turismo y desarrollo económico en España durante el franquismo, 1939-1975», en Revista de la Historia de la Economía y de la Empresa, v. VII, pp. 423-452.

VÁZQUEZ GONZÁLEZ, A. y GONZÁLEZ CÁRDENAS, E. (2007): «El relieve», en PILLET CAPDEPÓN, F. (Coord.): Geografía de Castilla-La Mancha. Ciudad Real, Almud, pp. 37-54.

VELASCO GONZÁLEZ, M. (2004): La política turística: gobierno administración turística en España (1952-2004). Valencia, Tirant lo Blanch.

VIZCAÍNO, J. A. (1966): Caminos de La Mancha. Madrid, Alfaguara.

VV.AA. (2006): Manifiesto «Por una Nueva Cultura del Territorio», Disponible en http:// age.ieg.csic.es/docs_externos/06-05-manifiesto_cultura_territorio.pdf

VV.AA. (2009): Castilla-La Mancha: materia prima para la imaginación. Toledo, Instituto de Promoción Turística de Castilla-La Mancha.

\section{RECURSOS WEB: [Actualizados a 14-01-2014]}

Boletín Oficial del Estado: http://www.boe.es/

Hemeroteca del Centro de Estudios de Castilla-La Mancha, Universidad de Castilla-La Mancha: http://ceclmdigital2.uclm.es/hemeroteca/cgi-bin/Pandora

- «Los componentes de «Suiza en la Aventura de la Mancha», llegaron a nuestra provincia», en Lanza, Ciudad Real, núm. 9.082 (23-09-1972), p. 1 y 4.

- «Los expertos en turismo visitaron Almagro, Las Virtudes, Valdepeñas, Villanueva de los Infantes, Ruidera y Argamasilla de Alba», en Lanza, Ciudad Real, núm. 9.083 (24-09-1972), p. 1 y 5.

- «Final de la andadura expedición «Suiza en la Aventura de la Mancha»», en Lanza, Ciudad Real, núm. 9.084 (26-09-1972), p. 1 y 5.

- «El epicentro de nuestro turismo», en Lanza, Ciudad Real, núm. 9.091 (04-10-1972), p. 13.

Hemeroteca de La Vanguardia: http://www.lavanguardia.com/hemeroteca/index.html

- «El señor Bassols presidió el V Pleno de la Comunidad Turística de La Mancha», en La Vanguardia Española, núm. 32.982, (21-06-1972), p. 11.

Instituto Nacional de Estadística: http://www.ine.es/

75 años del Parador de Manzanares:

http://www.parador.es/recursos/doc/Corporativo/Area_de_prensa/Notas_de_pre nsa/2008/711237922_24112008131716.pdf

\section{ARCHIVO:}

Ministerio de Educación, Cultura y Deporte. Archivo General de la Administración, Fondo Ministerio de Información y Turismo, caja 59260. 
